\title{
Management of immune dysfunction after adult cardiac surgery
}

\author{
J. Scott Rankin, MD, ${ }^{\mathrm{a}, \mathrm{d}}$ Olusola Oguntolu, MD, ${ }^{\mathrm{a}}$ Robert S. Binford, MD, ${ }^{\mathrm{a}}$ D. Scott Trochtenberg, MD, \\ Lawrence H. Muhlbaier, $\mathrm{PhD},{ }^{\mathrm{c}}$ and Charles W. Stratton, $\mathrm{MD}^{\mathrm{d}}$
}

\begin{abstract}
Objective: Pulmonary dysfunction/multiorgan failure syndrome is an important cause of mortality and morbidity after cardiac operations. In this series, results of immune augmentation were assessed in patients experiencing pulmonary dysfunction/multiorgan failure syndrome after cardiac surgery.
\end{abstract}

\begin{abstract}
Methods: Since 2002, 44 consecutive patients with primary antibiotic-refractory pulmonary dysfunction/multiorgan failure syndrome were treated with intravenous immunoglobulin $(0.3 \mathrm{~g} / \mathrm{kg} \times 5$ days; $1.5 \mathrm{~g} / \mathrm{kg}$ total dose $)$. Thirty patients had undergone complex valve or aortic surgery, and 14 patients had coronary bypass. Median age was 66 years, and risk profiles were especially high preoperatively. Clinical variables were assessed for 3 days prior $(-3)$ to beginning intravenous immunoglobulin (on day 0 ) and for 5 days afterward $(+5)$. A postoperative morbidity index was generated as a weighted sum of all relevant clinical variables. By using each patient as his or her own control, the therapeutic effect of intravenous immunoglobulin was assessed with linear regression of postoperative morbidity index over time with a spline and a knot at day 0 , coincident with beginning intravenous immunoglobulin.
\end{abstract}

Results: At day 0, all patients were deteriorating clinically and refractory to major antibiotics. Overall morbidity was high, and immunoglobulin-G levels, obtained in the last 14 patients, were consistently low. By using linear regression of postoperative morbidity index over time, intravenous immunoglobulin administration was associated with significant improvement in clinical status $(P<.0001)$. A total of 42 of 44 patients $(95 \%)$ recovered uneventfully to hospital discharge. No significant complications of intravenous immunoglobulin therapy occurred.

Conclusions: This experience suggests that management of immune dysfunction with intravenous immunoglobulin is safe and effective for treatment of primary pulmonary dysfunction/multiorgan failure syndrome after cardiac surgery. Expanded application seems indicated. (J Thorac Cardiovasc Surg 2011;142:575-80)

\section{"Still today, most of our postoperative problems can be related to the deleterious effects of cardiopulmonary bypass." \\ —John W. Kirklin, MD, Ward rounds, University of Alabama Hospital, July 1970}

Many postoperative complications after cardiac surgery are associated with some degree of immune dysregulation. ${ }^{1}$ Although exact mechanisms remain to be defined, gram-negative pneumonia with opportunistic organisms seem to require immune compromise, and problems such as renal failure and thrombocytopenia often may be related to inappropriate immune activation. In fact,

\footnotetext{
From the Centennial Medical Center, ${ }^{a}$ Nashville, Tenn; Meharry Medical College, ${ }^{b}$ Nashville, Tenn; Duke University Medical Center, ${ }^{\mathrm{c}}$ Durham, NC; and Vanderbilt University, ${ }^{\mathrm{d}}$ Nashville, Tenn.

Disclosures: Authors have nothing to disclose with regard to commercial support.

Read at the 36th Annual Meeting of The Western Thoracic Surgical Association, Ojai, California, June 23-26, 2010.

Received for publication June 25, 2010; revisions received Jan 10, 2011; accepted for publication April 15, 2011; available ahead of print July 4, 2011.

Address for reprints: J. Scott Rankin, MD, Department of Cardiac Surgery, Vanderbilt University, 320 Lynnwood Blvd, Nashville, TN 37205 (E-mail: jsrankinmd@cs. com).

$0022-5223 / \$ 36.00$

Copyright (c) 2011 by The American Association for Thoracic Surgery

doi:10.1016/j.jtcvs.2011.04.042
}

cardiac surgical patients may be predisposed to such problems, with a high incidence of critically ill compromised patients preoperatively, the additional immune depleting effects of cardiopulmonary bypass, ${ }^{2}$ and varying degrees of malnutrition early postoperatively. At present, problems related to pulmonary infection/dysfunction and multiorgan failure syndrome (PD/MFS) are increasing, ${ }^{3,4}$ especially in patients undergoing valve surgery, ${ }^{5}$ who require longer cardiopulmonary bypass runs. In 2002, after several deaths from postoperative pan-resistant gramnegative pneumonia, it seemed reasonable to explore other therapeutic options. Then, as now, no new gramnegative antibiotics were close to development, ${ }^{6-11}$ and after careful analysis of recent literature, it was elected to augment and attempt to "normalize" function of the immune system. ${ }^{1}$ The concept was to synergistically assist antibiotic control of infection and to modulate inappropriate immune activation. At the time, intravenous immune globulin (IVIG) was increasingly being used to restore immune function toward "normal" in multiple disorders, and application to patients postcardiac surgery seemed logical. In this report, the results of a clinical effort of immune augmentation/modulation using IVIG for primary PD/MFS after adult cardiac surgery are described. 


\section{Abbreviations and Acronyms \\ $\mathrm{IgG}=$ immunoglobulin $\mathrm{G}$ \\ IVIG $=$ intravenous immune globulin \\ $\mathrm{IVIgG}=$ intravenous immunoglobulin $\mathrm{G}$ \\ $\mathrm{PD} /=$ pulmonary infection/dysfunction and \\ MFS multiorgan failure syndrome \\ PMI = postoperative morbidity index}

\section{MATERIALS AND METHODS \\ Population}

The 44 patients described in this article represent a consecutive series of patients in whom isolated antibiotic-refractory PD/MFS developed after cardiac surgery by the first author from 2002 to 2010. Criteria for diagnosis included pulmonary infiltrates associated with pulmonary dysfunction and some degree of multiorgan failure, refractory to at least 24 hours of major antibiotic therapy. Outcomes of the first 15 patients have been published, ${ }^{1}$ and the procedures and individual patient characteristics of the whole series are listed in Table 1 . Thirty patients had undergone complex cardiac valve or aortic surgery, and 14 patients had coronary bypass. Median age was 66 years. Preoperatively, $98 \%$ of the patients had significant comorbidity, $66 \%$ presented acutely, $45 \%$ were hypoalbuminemic, and $32 \%$ had antecedent acute pulmonary derangement. Preoperative total serum globulin levels were normal in all patients. Preoperative IgG levels were low in some but were not obtained routinely. Fourteen of the 44 patients experienced significant postoperative bleeding, treated by blood component therapy, and 1 patient had required reoperation for bleeding.

\section{General Management Protocol}

Postoperatively, patients had combinations of worsening pulmonary infiltrates; persistent signs of sepsis (eg, high cardiac output, low systemic vascular resistance, chills, rigors, fever, and delirium); leukocytosis; deterioration of pulmonary mechanics; and impairment of pulmonary gas exchange, despite receiving at least 24 hours of major triple-drug intravenous antibiotics (consisting of combinations of piperacillin/tazobactam, cefepime, tobramycin, and meropenem; vancomycin was used only for specific indications). In general, the University of Kentucky antibiotic approach for management of hospital-acquired pneumonia was used, ${ }^{12}$ and having an effective antibiotic protocol seemed to be important.

In this series of patients, no other complications or sources of infection were present, such as gastrointestinal sepsis and so forth. All patients were moved back to an intensive care unit setting and had documentation of good cardiac status with a Swan-Ganz catheter and a transthoracic echocardiogram at the outset to rule out cardiac cause of pulmonary infiltrates and PD/MFS. Pulmonary cultures were obtained in all patients, including bronchial washings or protected brush cultures in patients undergoing therapeutic fiberoptic bronchoscopy. Renal failure was also developing in 28 of the 44 patients (64\%), manifested by oliguria or anuria with increasing creatinine, despite intravenous dopamine and diuretic support. Important general clinical management principles also were emphasized, such as early enteral nutrition, avoidance of total parenteral nutrition, minimization of central lines as sources of infection, aggressive pulmonary care, ongoing optimization of cardiopulmonary function, effective arrhythmia management, ${ }^{13}$ and standard postoperative care. If it seemed that prolonged supplemental enteral nutrition would be needed, a percutaneous endoscopic gastrostomy tube was placed. In cases associated with profound thrombocytopenia, anticoagulation with thrombin inhibitors and platelet transfusions were avoided, and the patients were treated with IVIG only.

\section{Intravenous Immune Globulin Therapy}

When the patient was documented as deteriorating despite conventional therapy, the family was engaged in a discussion of the situation and explained the potential advantages and complications of immune boost with IVIG. At the time, literature support existed for this form of immune intervention. ${ }^{14-22}$ All families agreed, and then high-dose IVIG therapy (Carimune, ZLB Behring Inc, King of Prussia, Pa) was begun at a dose of 18 or $24 \mathrm{~g}$ per day (depending on the size of the patient; $\sim 0.3 \mathrm{~g} / \mathrm{kg}$ ) intravenously for 5 days to a total dose of $1.5 \mathrm{~g} / \mathrm{kg}$. In the subsequent analysis, the first day of IVIG infusion was considered IVIG day 0.

\section{Analysis Protocol}

Perioperative clinical variables were combined into one number, the postoperative morbidity index (PMI), to quantify overall time varying changes in clinical status. Clinical variables were worsening pulmonary infiltrates (I) on the chest radiograph; leukocytosis (L); pulmonary dysfunction (P); ventilator requirement $(\mathbf{V})$; septic shock $(\mathbf{S})$; renal $(\mathbf{R})$, gastrointestinal (G), and hepatic (H) dysfunction; thrombocytopenia (T); and delirium (D). Variables were documented by retrospective chart review for 3 days prior (day -3) to beginning IVIG therapy (on day 0) and for 5 days afterward (day +5). PMI was used to quantify the clinical condition in a given patient, on a given day, with one number. The "weighting" of each variable was determined before the analysis began, based on estimated subjective clinical importance. PMI was calculated as the sum of I: $1=$ minor infiltrate in one lobe, $3=$ moderate infiltrates in more than 1 lobe, $5=$ severe infiltrates throughout both lungs, $7=$ complete pulmonary "white-out"; $\mathbf{L}: 1$ for each $2 \mathrm{~K}$ increase in white blood count above 10K; $\mathbf{P}$ was divided into sputum: $1=$ severe cough only, 2 = purulent sputum, 3 = positive sputum culture; increased work of breathing: $1=$ mild, $2=$ moderate, $3=$ severe; and oxygen requirement: $1=$ mild $\left(\mathrm{O}_{2}\right.$ requirement $=40 \%), 2=$ moderate $\left(50 \%-70 \% \mathrm{O}_{2}\right), 3=$ severe $(100 \%$ $\mathrm{O}_{2}$ ); V: 5 for requirement of mechanical ventilation; $\mathbf{S}: 3$ for mean arterial pressure less than $65 \mathrm{~mm} \mathrm{Hg}$ with cardiac index greater than 3.0 on intravenous catecholamines; R: 1 for each $0.4 \mathrm{mg} / \mathrm{dL}$ increase in creatinine greater than $1.5 \mathrm{mg} / \mathrm{dL} ; \mathbf{G}: 2$ for "ileus" diagnosed on abdominal radiograph; H: 2 for any elevation in bilirubin or hepatic enzymes documented; T: 2 for platelet count less than $60 \mathrm{~K}$; and D: 2 for delirium requiring pharmacologic therapy. By using each patient as his or her own control, the therapeutic effect of intravenous immunoglobulin G (IVIgG) was assessed with linear regression analysis of PMI over time with a spline and a knot at day 0 , coincident with beginning IVIgG.

This trial of IVIG for the purpose of treating PD/MFS was initiated within a clinical cardiac surgical practice in the setting of a worsening high-risk problem with limited available solutions. An off-label application of an Food and Drug Administration-approved drug was used, and the concept was based on existing literature support at the time. ${ }^{14-26}$ The chart review and analysis was performed at a later date under a waiver of informed consent by the Western Institutional Review Board for assessment of an individual surgeon's outcomes with deidentified patient variables.

\section{RESULTS}

At the time of initiation of IVIG therapy, every patient was worsening rapidly, with impending need for reintubation or ventilatory requirement in most, despite broad-spectrum intravenous antibiotics for at least 24 hours previously. No patient in this series had other complications or evidence of alternative sources of infection. In the linear regression analysis of PMI over the 3 days before IVIG, the patients' clinical status was deteriorating significantly (slope $=3.59$, standard error $=0.41, \mathrm{t}=8.62, P<.0001)$. When the decision for IVIgG was made (day 0), morbidity included $\mathbf{I}-100 \%$, 
L- $95 \%, \mathbf{P}-95 \%$, V- $48 \%$, S- $25 \%$, R- $64 \%$, G- $20 \%, \mathbf{H}-7 \%$, $\mathbf{T}-32 \%$, and D- $9 \%$. IgG levels, obtained in the last 14 patients, were consistently low (Table 1). After beginning IVIG at day 0 , improvement in clinical course was observed uniformly over the subsequent 5 days (slope $=-1.98$, standard error $=0.20, \mathrm{t}=9.75, P<.0001)$. In the spline function analysis and using each patient as his or her own control, IVIG administration was associated with significant improvement in clinical status $(P<.0001)$, as evidenced by a decrease in PMI toward normal over the course of immune augmentation (Figure 1). Despite serious baseline profiles at day 0, 42 of 44 patients $(95 \%)$ recovered uneventfully to hospital discharge. No significant complications of IVIgG therapy occurred.

In 1 patient exhibiting profound thrombocytopenia with schistocytes and a negative heparin antibody test result, plasmapheresis was used over 3 days, in addition to concomitant IVIG therapy, with a prompt clinical response. This patient also received extra doses of immunoglobulin to compensate for losses due to plasma exchange. Pulmonary cultures were positive in less than one third of patients, usually with resistant gram-negative organisms; however, Pneumococcus was present in 1 patient. One patient had an initial good response, but progressive sepsis then developed and he died. He had bled into his right lung early postoperatively, and it was difficult to clear the infection in his lung. The second patient in the series who died had a hypoxic respiratory arrest after removing his oxygen mask during an episode of delirium. He was responding to IVIG nicely at the time, and more careful observation might have prevented the death. Although recovery of serum creatinine was prolonged in several patients with acute renal failure, all surviving patients recovered renal function to preoperative levels.

\section{DISCUSSION}

An in-depth discussion of immune function in this setting and the mechanisms of IVIG action has been published. ${ }^{1}$ Briefly, IVIG contains active human antibodies from more than 4000 patients in a region. Administration in patients with PD/MFS may provide attack antibodies to augment control of any given infection, but perhaps more important, modulatory antibodies regulate the immune response, resolving inappropriate immune activation and inflammation. Whether considering inflammatory mediators, activated complement, inappropriate autoantibodies, or bacterial superantigens, IVIG in these doses functions to return the immune system toward normal after the dysregulating effects of surgery and cardiopulmonary bypass. ${ }^{1}$ Although IVIG is a human blood product, sterilization using a nanofiltration system has been effective, with no disease transmission documented in millions of doses..$^{20,21}$ At the doses used in this article, renal injury associated with globulin administration has been rare and was nonexistent in this series.

Much of the organ toxicity associated with pulmonary infection is mediated by microbial products called "superantigens" 23,24 that cause direct cellular injury and activate $\mathrm{T}$ lymphocytes to release abundant cytokines. Neutralizing antibodies to superantigens exert strong antitoxin effects, with immunomodulatory consequences. Scavenging of superantigens is a major action of IVIG for treatment of multiorgan failure associated with systemic infection, and IVIG seemed effective in reversing organ dysfunction in the present series. In fact, we have never before had a clinical approach that could directly treat, and almost immediately reverse, postoperative renal failure. Patients exhibiting thrombocytopenia probably also are responding to one of several superantigens, or even uncontrolled autoantibodies, which induce aggregation and peripheral deposition of platelets, and further contribute to organ failure by causing microcirculatory underperfusion. ${ }^{26}$ IVIG therapy seemed effective in reversing thrombocytopenia, and the addition of plasmapheresis in an extreme case was adjunctive. It has been efficacious to apply IVIG (and adjunctive plasmapheresis when necessary) to cases of early postoperative profound thrombocytopenia, potentially caused by PF4 heparin antibodies (heparin-induced thrombocytopenia), thrombotic thrombocytopenic purpura-like antibodies, or infectious causes. ${ }^{27,28}$ In fact, most postoperative microangiopathies may be just further examples of "immune dysregulation syndrome."

In the present study, patients who developed PD/MFS often were elderly, had significant comorbidity, and were hospitalized with acute illness, exhibiting nutritional and potentially immunologic depletion on admission. Hypoalbuminemia was an important marker and may reflect nutritionally based inability to synthesize protein, and thus immunoglobulins. Acquired immune defects may even be required for gram-negative pneumonia to occur. Patients frequently displayed preoperative pulmonary injury or infection and were primarily complex valve cases. One might speculate that longer cardiopulmonary bypass and endotracheal intubation times could be important in the pathogenesis. A history of postoperative bleeding (a known risk factor for infection) was common in this population, and when treated with blood component therapy devoid of globulins may have led to worse depletion of immunoglobulins.

Several limitations of this study need to be documented. First, the PMI was developed prospectively to quantify clinical status with one number. The exact scores, however, were selected arbitrarily, based (one might say) on "expert opinion." A more objective score assignment might be useful in the future, using, for example, coefficients generated by logistic regression analysis. Several of the variables, such as radiographic degree of lung infiltrates, also were subjective. Thus, the PMI has to be considered a semiquantitative tool, although directional clinical changes and the high degree of ultimate recovery would be independent of exact scores assigned. This study is a retrospective analysis 
TABLE 1. Patient characteristics

\begin{tabular}{|c|c|c|c|c|c|c|c|}
\hline$\underline{\text { Patient }}$ & Age, $y$ & Gender & CM & Reoperation & Cause & $\begin{array}{c}\text { NYHA } \\
\text { anginal class }\end{array}$ & $\begin{array}{l}\text { NYHA heart } \\
\text { failure class } \\
\end{array}$ \\
\hline 1 & 56 & M & 1 & No & IE & I & IV \\
\hline 2 & 77 & M & 4 & No & CAD & I & III \\
\hline 3 & 62 & M & 4 & No & Ischemic mitral disease & IV & I \\
\hline 4 & 41 & $\mathrm{~F}$ & 2 & No & Rheumatic disease & I & IV \\
\hline 5 & 75 & M & 1 & No & CAD & IV & I \\
\hline 6 & 69 & M & 3 & No & $\mathrm{CAD}$ & IV & I \\
\hline 7 & 78 & M & 4 & No & Prolapse & I & IV \\
\hline 8 & 57 & M & 2 & No & CAD & IV & I \\
\hline 9 & 54 & M & - & No & Marfan syndrome or other connective tissue disease. & I & IV \\
\hline 10 & 69 & M & 2 & No & Prolapse & I & IV \\
\hline 11 & 77 & M & 3 & No & Calcified valve disease & I & IV \\
\hline 12 & 77 & M & 3 & No & Prolapse & I & IV \\
\hline 13 & 69 & $\mathrm{~F}$ & 1 & Yes & Prolapse & I & III \\
\hline 14 & 78 & $\mathrm{~F}$ & 4 & No & CAD & IV & I \\
\hline 15 & 67 & $\mathrm{~F}$ & 4 & Yes, $3 \times$ & Ischemic mitral disease & I & IV \\
\hline 16 & 59 & M & 2 & No & CAD & IV & I \\
\hline 17 & 81 & $\mathrm{~F}$ & 1 & No & Calcified valve disease & I & IV \\
\hline 18 & 67 & M & 1 & No & CAD & I & III \\
\hline 19 & 51 & M & 2 & No & CAD & IV & I \\
\hline 20 & 60 & M & 3 & Yes & CAD & IV & I \\
\hline 21 & 75 & M & 3 & No & $\mathrm{CAD}$ & III & I \\
\hline 22 & 75 & M & 3 & No & $\mathrm{CAD}$ & I & III \\
\hline 23 & 57 & $\mathrm{~F}$ & 1 & No & Rheumatic disease & I & III \\
\hline 24 & 53 & M & 1 & No & $\mathrm{CAD}$ & IV & I \\
\hline 25 & 67 & M & 4 & No & PAD & I & III \\
\hline 26 & 44 & M & 3 & No & CAD & IV & I \\
\hline 27 & 60 & M & 3 & No & Marfan syndrome or other connective tissue disease & I & IV \\
\hline 28 & 79 & M & 3 & No & Ischemic mitral disease & I & IV \\
\hline 29 & 70 & M & 1 & No & $\mathrm{CAD}$ & IV & I \\
\hline 30 & 59 & $\mathrm{~F}$ & 1 & No & Calcified valve disease & I & III \\
\hline 31 & 49 & M & 2 & Yes, $5 \times$ & Marfan syndrome or other connective tissue disease & I & I \\
\hline 32 & 69 & M & 1 & No & Calcified valve disease & I & III \\
\hline 33 & 67 & $\mathrm{~F}$ & 2 & No & PAD & I & IV \\
\hline 34 & 77 & M & 2 & No & Calcified valve disease & I & IV \\
\hline 35 & 57 & $\mathrm{~F}$ & 2 & No & CAD & IV & I \\
\hline 36 & 77 & $\mathrm{~F}$ & 1 & No & PAD & I & IV \\
\hline 37 & 77 & M & 3 & No & Prolapse & I & IV \\
\hline 38 & 80 & $\mathrm{~F}$ & 2 & No & Calcified valve disease & I & IV \\
\hline 39 & 39 & $\mathrm{~F}$ & 3 & Yes & Congenital heart disease & I & IV \\
\hline 40 & 57 & M & 3 & No & CAD & I & III \\
\hline 41 & 62 & $\mathrm{~F}$ & 3 & Yes & $\mathrm{HOC}$ & I & III \\
\hline 42 & 59 & M & 2 & Yes & IE & I & IV \\
\hline 43 & 77 & M & 3 & Yes & PAD & I & IV \\
\hline 44 & 90 & $\mathrm{M}$ & 2 & No & Prolapse & I & IV \\
\hline
\end{tabular}

$C M$, Number of comorbidities; $C A D$, coronary artery disease; $I E$, infectious endocarditis; $P A D$, pure annular dilatation; $H O C$, hypertrophic obstructive cardiomyopathy; $N Y H A$, New York Heart Association; $C H F$, congestive heart failure; $N$, normal; $P E$, pulmonary edema; $B S$, balloon pump for shock; $A P$, acute presentation; $C$, coronary bypass; $A$, aortic valve; $M$, mitral valve; $T$, tricuspid valve; $V R$, valve repair/replacement; $V S D$, patch closure of ventricular septal defect; Bentall, aortic root replacement; Smy, septal myectomy; $A A A$, ascending aortic aneurysm; $T r$, transfusion of $\geq 4$ units of packed red cells, $\geq 4$ units of fresh-frozen plasma, and $\geq 6$ units of platelets (patient 13 required reoperation for bleeding); $\operatorname{Ig} G$, postoperative immunoglobulin G levels. Normal albumin for this laboratory is $>3.4$, and normal $\operatorname{IgG}$ is $>680$.

of a clinical experience, and undefined or confounding variables may have influenced results. However, with such a consistent response in 44 consecutive patients, and with the strong results of the spline analysis using each patient as his or her own control, the presence of a significant treatment effect is highly probable. In the authors' opinion, a randomized trial now would be unethical, although future studies of mechanisms seem indicated. Finally, IgG levels were only available in the latter part of the series, but it did seem that PD/MFS was associated with low Ig levels. 
TABLE 1. Continued

\begin{tabular}{|c|c|c|c|c|c|c|}
\hline $\begin{array}{c}\text { Preoperative } \\
\text { hemodynamics }\end{array}$ & $\begin{array}{c}\text { Preoperative } \\
\text { serum albumin }\end{array}$ & $\begin{array}{c}\text { Acute } \\
\text { presentation }\end{array}$ & Procedure & Pump time & Transfusion & $\begin{array}{c}\text { Postoperative } \\
\text { IgG levels } \\
\end{array}$ \\
\hline PE & 2.9 & $\mathrm{Y}$ & AMT-VR, VSD & 3:06 & No & - \\
\hline $\mathrm{N}$ & 2.8 & $\mathrm{~N}$ & $\mathrm{C} \times 4$ & $1: 36$ & No & - \\
\hline $\mathrm{N}$ & 3.4 & $\mathrm{Y}$ & AM-VR, $\mathrm{C} \times 4$ & 4:05 & No & - \\
\hline $\mathrm{N}$ & 3.8 & $\mathrm{Y}$ & MVR & $2: 06$ & No & - \\
\hline $\mathrm{N}$ & 2.7 & $\mathrm{Y}$ & $\mathrm{C} \times 2$ & $1: 05$ & Yes & - \\
\hline $\mathrm{N}$ & 3.6 & $\mathrm{Y}$ & $\mathrm{C} \times 4$ & $2: 19$ & No & - \\
\hline $\mathrm{N}$ & 3.4 & Y & MVR, $C \times 2$ & $2: 56$ & No & - \\
\hline $\mathrm{N}$ & 2.7 & $\mathrm{Y}$ & $\mathrm{C} \times 5$ & $2: 22$ & No & - \\
\hline $\mathrm{N}$ & 3.0 & Y & Bentall & $3: 19$ & Yes & - \\
\hline PE & 2.0 & $\mathrm{Y}$ & MT-VR & $3: 21$ & Yes & - \\
\hline $\mathrm{N}$ & 3.3 & $\mathrm{~N}$ & A-VR, $C \times 4$ & $2: 40$ & Yes & - \\
\hline $\mathrm{PE}$ & 2.2 & $\mathrm{Y}$ & MVR, $\mathrm{C} \times 1$ & 3:01 & No & - \\
\hline $\mathrm{N}$ & 3.8 & $\mathrm{~N}$ & MVR, radiofrequency ablation & $1: 54$ & Yes & - \\
\hline BS & 2.7 & $\mathrm{Y}$ & $\mathrm{C} \times 4$ & $1: 26$ & Yes & - \\
\hline $\mathrm{N}$ & 3.6 & $\mathrm{Y}$ & MT-VR & $3: 40$ & Yes & - \\
\hline $\mathrm{N}$ & 3.1 & $\mathrm{Y}$ & $\mathrm{C} \times 4$ & $2: 30$ & No & - \\
\hline $\mathrm{N}$ & 2.8 & $\mathrm{Y}$ & $\mathrm{A}-\mathrm{VR}, \mathrm{C} \times 1$ & $1: 58$ & No & - \\
\hline $\mathrm{N}$ & 2.9 & $\mathrm{~N}$ & MVR, $\mathrm{C} \times 3$ & $3: 30$ & No & - \\
\hline $\mathrm{N}$ & 3.0 & $\mathrm{Y}$ & $\mathrm{C} \times 4$ & $1: 52$ & No & - \\
\hline $\mathrm{N}$ & 3.9 & $\mathrm{~N}$ & $\mathrm{C} \times 3$ & $3: 48$ & Yes & - \\
\hline $\mathrm{N}$ & 4.0 & $\mathrm{Y}$ & $\mathrm{C} \times 4$ & 2:01 & Yes & - \\
\hline $\mathrm{N}$ & 3.9 & $\mathrm{~N}$ & $\mathrm{C} \times 4$ & $1: 40$ & No & - \\
\hline $\mathrm{N}$ & 3.8 & $\mathrm{~N}$ & MVR & 3:02 & No & - \\
\hline $\mathrm{N}$ & 3.5 & Y & $\mathrm{C} \times 3$ & $1: 33$ & No & - \\
\hline $\mathrm{N}$ & 3.9 & Y & MT-VR, radiofrequency ablation & $2: 01$ & No & - \\
\hline $\mathrm{N}$ & 4.2 & $\mathrm{Y}$ & $\mathrm{C} \times 1$ & $1: 25$ & Yes & - \\
\hline $\mathrm{N}$ & 2.9 & $\mathrm{Y}$ & AVR, AAA & $2: 12$ & No & - \\
\hline PE & 3.2 & $\mathrm{Y}$ & MVR, $\mathrm{C} \times 4$ & $2: 46$ & No & - \\
\hline $\mathrm{N}$ & 3.7 & $\mathrm{Y}$ & $\mathrm{C} \times 5$ & $1: 43$ & No & - \\
\hline $\mathrm{N}$ & 3.5 & $\mathrm{~N}$ & AVR, $\mathrm{C} \times 4$ & $1: 50$ & No 315 & - \\
\hline $\mathrm{N}$ & 3.4 & $\mathrm{~N}$ & TAA & $6: 30$ & Yes & 481 \\
\hline $\mathrm{N}$ & 3.5 & $\mathrm{~N}$ & AVR, C $\times 1$, SMy & $2: 38$ & No 269 & 359 \\
\hline $\mathrm{N}$ & 3.4 & $\mathrm{~N}$ & MT-VR, $\mathrm{C} \times 1$ & 4:06 & No 498 & 525 \\
\hline $\mathrm{N}$ & 3.2 & $\mathrm{Y}$ & AM-VR, $\mathrm{C} \times 2$, AAA, radiofrequency ablation & $4: 33$ & No & 368 \\
\hline $\mathrm{N}$ & 3.7 & $\mathrm{Y}$ & $\mathrm{C} \times 2$ & $1: 33$ & No & 255 \\
\hline PE & 3.0 & $\mathrm{Y}$ & AMT-VR, radiofrequency ablation & $3: 35$ & Yes & 487 \\
\hline $\mathrm{N}$ & 3.4 & Y & AM-VR, radiofrequency ablation & 4:08 & Yes & 546 \\
\hline $\mathrm{N}$ & 3.7 & $\mathrm{~N}$ & AVR, root enlargement & $3: 20$ & No & 537 \\
\hline $\mathrm{N}$ & 4.1 & $\mathrm{~N}$ & MVR, radiofrequency ablation & $4: 26$ & No & 704 \\
\hline $\mathrm{N}$ & 3.7 & $\mathrm{~N}$ & $\mathrm{C} \times 3$, radiofrequency ablation & $3: 26$ & No & 358 \\
\hline $\mathrm{N}$ & 2.9 & $\mathrm{~N}$ & MVR, C×1, SMy & 3:01 & Yes & 587 \\
\hline $\mathrm{N}$ & 3.5 & $\mathrm{Y}$ & MVR & 3:06 & No & 788 \\
\hline $\mathrm{N}$ & 3.0 & $\mathrm{Y}$ & AMT-VR, radiofrequency ablation & $4: 20$ & No & 105 \\
\hline $\mathrm{PE}$ & 2.9 & $\mathrm{Y}$ & MVR, radiofrequency ablation & $2: 52$ & No 467 & 386 \\
\hline
\end{tabular}

Future analysis of postoperative immunoglobulin levels relative to outcomes could be illuminating.

In current practice, postoperative PD/MFS is the most important cause of morbidity and mortality. ${ }^{29}$ Moreover, the incidence may be increasing with the emergence of multidrug-resistant bacteria. Strategies to control the problem include better antibiotic stewardship, and important antibiotic protocols have been developed that can reverse antibiotic resistance patterns. Potential sources of nosocomial infection also should be addressed, ${ }^{30}$ and it is 


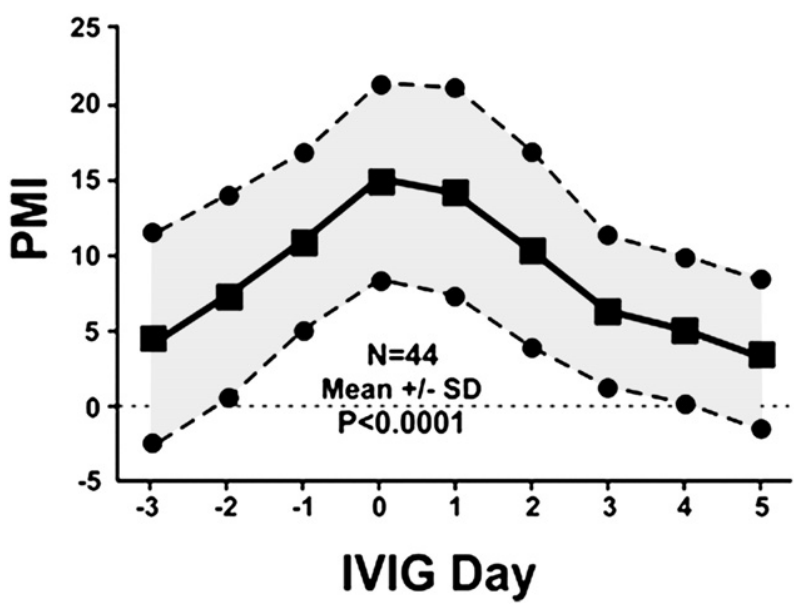

FIGURE 1. Mean \pm standard deviation of course of PMI for 3 days before $(-3)$ to 5 days after $(+5)$ beginning IVIgG therapy in 44 postoperative patients. IVIgG therapy was begun on day zero (0). IVIgG was associated with a consistent reversal of worsening of postoperative morbidity and a highly significant treatment effect, using each patient as his/her own control $(P<.0001)$. See text for details. PMI, Postoperative morbidity index; $S D$, standard deviation; $I V I G$, intravenous immunoglobulin.

possible that operating room anesthesia ventilators have been significant culprits, providing a reservoir in many hospitals for resistant gram-negative pulmonary infections. Better infection control may be the ultimate approach to this problem, although it is unlikely that postoperative pneumonia after cardiac surgery could be completely eliminated. Finally, correlating our results with the findings of the ESSICS trial ${ }^{31}$ is difficult. In the 2 series, patient selection probably was different, the IVIG may not have been as active as currently used preparations, and, most important, doses used in the ESSICS trial were clearly subtherapeutic. $^{32}$ Thus, the conclusion of that trial that IVIG was ineffective in postoperative cardiac surgery patients could have been an artifact of study design.

\section{CONCLUSIONS}

IVIG administered to patients experiencing antibioticresistant PD/MFS after cardiac surgery promptly and effectively reversed clinical deterioration and seemed efficacious and safe. Immune dysregulation may play an important role in PD/MFS, and immune augmentation with IVIG offers the exciting possibility of effectively treating one of the major problems encountered in cardiac surgical practice today. Studies of immunomodulatory mechanisms also seem indicated.

\section{References}

1. Rankin JS, Glower DD, Teichmann TL, et al. Immunotherapy for refractory pulmonary infection after adult cardiac surgery: immune dysregulation syndrome. J Heart Valve Dis. 2005;14:783-91.

2. Kirklin JK, Kirklin JW. Cardiopulmonary bypass for cardiac surgery. In: Sabiston DC Jr., Spencer FC, eds. Surgery of the Chest. 5th ed. Philadelphia: WB Saunders Company; 1990:1116.
3. Peterson ED, Coombs LP, Ferguson TB, et al. Hospital variability in length of stay after coronary artery bypass surgery: results from the Society of Thoracic Surgeon's National Cardiac Database. Ann Thorac Surg. 2002;74:464-73.

4. Rankin JS, Orozco RE, Rodgers TL, et al. Several new considerations in mitral valve repair. J Heart Valve Dis. 2004;13:399-409.

5. Lee RL, Li S, Rankin JS, et al. Fifteen-year outcome trends for valve surgery in North America. Ann Thorac Surg. 2011;91:677-84.

6. Rice LB, Scheife RT. Antimicrobial resistance: understanding therapeutic choices. J Hum Pharmacol Drug Ther. 1999;19:111S-37.

7. Wenzel RP. The antibiotic pipeline-challenges, costs and values. $N$ Engl J Med. 2004;351:523-6.

8. CDC-Anon, National Nosocomial Infections Surveillance (NNIS) system report, data summary from January 1992-June 2003. Am J Infect Control. 2003;31:481-98.

9. Empey KM, Rapp RP, Evans ME. The effect of an antimicrobial formulary change on hospital resistance patterns. Pharmacotherapy. 2002;22:81-7.

10. Rapp RP, Evans ME, Martin C, et al. Drug costs and bacterial susceptibility after implementing a single-fluoroquinolone use policy at a university hospital. Curr Med Res Opin. 2002;20:469-76.

11. Martin C, Ofotokun I, Rapp R, et al. Results of an antimicrobial control program at a university hospital. Am J Health Syst Pharm. 2005;62:732-8.

12. Rapp RP. University of Kentucky Guide to Empiric Antimicrobial Therapy. Lexington, KY: University of Kentucky Press; 2002.

13. Rankin JS. Amiodarone and cardiac surgery (Letter to the Editor). J Thorac Cardiovasc Surg. 2007;134:271.

14. Aghamohammadi A, Moin M, Farhoudi A, et al. Efficacy of intravenous immunoglobulin on the prevention of pneumonia in patients with agammaglobulinemia. FEMS Immunol Med Microbiol. 2004;40:113-8.

15. Busse PJ, Razvi S, Cunningham-Rundles C. Efficacy of intravenous immunoglobulin in the prevention of pneumonia in patients with common variable immunodeficiency. J Allergy Clin Immunol. 2002;109:1001-4.

16. Kress HG, Scheidewig C, Schmidt H, et al. Reduced incidence of postoperative infection after intravenous administration of an immunoglobulin A- and immunoglobulin M- enriched preparation in anergic patients undergoing cardiac surgery. Crit Care Med. 1999;27:1281-7.

17. Friedrich I, Silber RE, Baumann B, et al. IGM-enriched immunoglobulin preparation for immunoprophylaxis in cardiac surgery. Eur J Med Res. 2002; 7:544-50.

18. Pilz G, Appel R, Kreuzer E, et al. Comparison of early IgM-enriched immunoglobulin vs polyvalent IgG administration in score-identified postcardiac surgical patients at high risk for sepsis. Chest. 1997;111:419-26.

19. Pilz G, Kreuzer E, Kaab S, et al. Early sepsis treatment with immunoglobulins after cardiac surgery in score-identified high risk patients. Chest. 1994;105:76-82.

20. Spath PJ. Structure and function of immunoglobulins. Sepsis. 1999;3:197-218.

21. Simon HU, Spath PJ. IVIG-mechanisms of action. Allergy. 2003;58:543-52.

22. Perex CM, Kubak BM, Cryer HG, et al. Adjunctive treatment of streptococcal toxic shock syndrome using intravenous immunoglobulin: case report and review. Am J Med. 1997;102:111-3.

23. Papageorgiou AC, Acharya KR. Microbial superantigens: from structure to function. Trends Microbiol. 2000;8:369-75.

24. McCormick JK, Yarwood JM, Schlievert PM. Toxic shock syndrome and bacterial superantigens: an update. Annu Rev Microbiol. 2001;55:77-104.

25. Norrby-Teglund A, Kaul R, Low DE, et al. Evidence for the presence of streptococcal-superantigen-neutralizing antibodies in normal polyspecific immunoglobulin G. Infect Immunol. 1996;64:5395-8.

26. Moake JL. Mechanisms of disease: thrombotic microangiopathies. N Engl J Med. 2002;347:589-600.

27. Saltzman DJ, Chang JC, Jimenez JC, et al. Postoperative thrombotic thrombocytopenic purpura after open heart operations. Ann Thorac Surg. 2010;89:119-23.

28. Welsby IJ, Um J, Milano CA, et al. Plasmapheresis and heparin reexposure as a management strategy for cardiac surgical patients with heparin-induced thrombocytopenia. Anesth Analg. 2010;110:30-5.

29. Rankin JS, Burrichter CA, Walton-Shirley MK, et al. Trends in mitral valve surgery: a single practice experience. J Heart Valve Dis. 2009;18:359-66.

30. Babcock HM, Zack JE, Garrison T, et al. An educational intervention to reduce ventilator-associated pneumonia in an integrated health system. Chest. 2004;125: 2224-31.

31. Werdan K, Pilz G, Müller-Werdan U, et al. Immunoglobulin G treatment of postcardiac surgery patients with score-identified severe systemic inflammatory response syndrome-the ESSICS study*. Crit Care Med. 2008;36:716-23.

32. Turgeon AF, Hutton B, Fergusson DA, et al. Meta-analysis: intravenous immunoglobulin in critically ill adult patients with sepsis. Ann Intern Med. 2007; 146:193-203. 